\title{
Occupational Exposure of Healthcare Workers during COVID-19 Field Surveillance Activities in South India: A Cross-Sectional Qualitative Study
}

\author{
Surya Srinivasan, Shailaja Tetali* \\ Public Health Foundation of India (Indian Institute of Public Health), Hyderabad, India \\ Email: *shailaja.t@iiphh.org
}

How to cite this paper: Srinivasan, S. and Tetali, S. (2021) Occupational Exposure of Healthcare Workers during COVID-19 Field Surveillance Activities in South India: A Cross-Sectional Qualitative Study. Open Journal of Epidemiology, 11, 446-456.

https://doi.org/10.4236/ojepi.2021.114036

Received: August 19, 2021

Accepted: November 13, 2021

Published: November 16, 2021

Copyright $\odot 2021$ by author(s) and Scientific Research Publishing Inc. This work is licensed under the Creative Commons Attribution International License (CC BY 4.0).

http://creativecommons.org/licenses/by/4.0/

\begin{abstract}
Context: Health Care Workers (HCWs) involved in field-level activities are exposed to COVID-19 which puts them under physical and psychological stress. Aim: The objective of this study was to understand the perception of the health care workers regarding their occupational exposure to COVID-19, including the safety measures used during field surveillance activities. Settings and Design: This cross-sectional study was conducted from June 2020 to July 2020 among the health care workers involved in COVID-19 field containment activities in two south Indian states-Telangana and Tamil Nadu. Methods and Material: Respondents were purposively sampled based on their involvement in the COVID-19 field level activities. Sixteen In-Depth Interviewees (IDIs) were conducted telephonically with medical officers, district epidemiologists, community health workers, sanitary workers, emergency medical technicians, and ambulance coordinators. Statistical Analysis Used: IDIs were analyzed using manual thematic analysis. Results: Seven themes and sub-themes emerged: awareness and training, occupational exposure to COVID-19 and duration, safety measures, occupational burnout, social stigma, psychological violence, and facilitating factors. Respondents felt a high level of occupational exposure to COVID-19 in addition to increased workload and stress due to fear of infection, shortage of workforce, denial of week off, psychological violence, and social stigma which affected them deeply. Support from supervisors and family, and measures ensuring the safety of women were facilitating factors to cope with the situation. Conclusions: It is important to safeguard the general and mental health of field-level health workers involved in COVID-19 activities, to keep their morale high during the continuing pandemic.
\end{abstract}

\section{Keywords}

Occupational Exposure, COVID-19, Field Surveillance, Healthcare Workers 


\section{Introduction}

Contact tracing is an essential public health tool in breaking the chain of transmission of any infectious disease. Similarly, the strategies to reduce the transmission of COVID-19 include case identification, isolation, testing and care, and contact tracing and quarantining. Contact tracing requires the identification of persons exposed to confirmed cases and following them up for 14 days [1]. Considering the nature of the transmission and mode of infection of COVID-19, some occupations present an increased risk of exposure and infection with Severe Acute Respiratory Syndrome Coronavirus 2 (SARS-CoV-2). One such occupation is Health Care Workers (HCWs) [2].

During the 2014 Ebola outbreak in Nigeria, several community health workers were deployed for contact tracing, community sensitization, promotion of epidemiologically and culturally appropriate protective practices, and data collection [3]. Similarly, during the current COVID-19 pandemic in India, Accredited Social Health Activists (ASHA) workers were deployed to conduct house-to-house surveys as a part of the Ministry of Health and Family Welfare's Model Micro Plan for Containing Local Transmission of Coronavirus Disease [4]. The tasks entrusted to ASHA workers varied from reporting on symptomatic cases, tracing contacts, maintaining documentation, monitoring the situation, and creating community awareness on the pandemic [4].

Frontline health workers are at an increased risk of COVID-19 due to pathogen exposure, long working hours, psychological distress, fatigue, occupational burnout, stigma, and physical and psychological violence [5]. ASHA workers have been stigmatized while conducting door-to-door surveys, fearing that they are the ones spreading the infection [4]. Since COVID-19 is a recent disease, published literature in India on the occupational exposure of a wide range of fieldlevel HCW to the pandemic is scarce. This study helps us better understand HCW s' perspectives on occupational exposure to COVID-19 and the safety measures followed during field surveillance activities in South India.

\section{Methods}

In this cross-sectional study, 16 In-Depth Interviewees (IDIs) were conducted in two south Indian states, Tamil Nadu, and Telangana, during June-July 2020. Purposive sampling was used for recruitment. The study participants represented HCW from Primary health centers, Municipal corporations, the Joint Directorate of health service, and the Deputy Directorate of health service. They were included due to their involvement in COVID-19, for us to be able to better understand their perspectives on occupational exposure and safety measures followed during COVID-19 field surveillance activities.

Participants included both the higher officials at the planning level, i.e., District epidemiologist, Medical officers, District sanitary inspector, and District ambulance coordinator, as well as the community level workers, i.e., ASHA, Auxiliary Nurse Midwife (ANM), Village Health Nurses (VHN), Urban Health Nurses, sanitary workers, emergency medical technicians, and ambulance coordinators. Qu- 
alitative In-Depth Interviewees (IDIs) were conducted telephonically by a trained researcher with a Master's degree in Public Health. A semi-structured interview guide was prepared based on a thorough literature review. Pre-specified themes were developed with open-ended questions (Annexure) to elicit respondents' perceptions of their occupational exposure during field surveillance activities. Questions covered themes on awareness, training, occupational burnout, social stigma, psychological distress, psychological violence, and preventive measures followed to safeguard themselves in the field.

Interviewees were conducted in Hindi, Telugu, and Tamil at the respondent's convenient time, and lasted between 30 to 50 minutes each. Data was collected until it reached saturation level where further exploration failed to provide new information. All the interview notes were transcribed into a word document immediately after each interview and translated into English.

Manual thematic analysis was used to analyze the IDIs. Line-by-line coding was performed by identifying units of analysis. Patterns were formed according to existing codes and were grouped under sub-themes. Final themes were then formed, from which abstraction of the whole data was obtained. In addition to the pre-specified themes, a few new themes evolved during the process of analysis.

Ethical approval was obtained from the institutional Ethics Committee, Indian Institute of Public Health, Hyderabad. Government health care officials who were engaged in the containment activities of both states were contacted telephonically to obtain permission for the study. Verbal consent was obtained from participating health care workers. All documents, notes, memos, audio recordings were kept confidential, and all digital documents were encrypted and stored in a password-protected computer.

\section{Results}

The socio-demographic characteristics of the 16 in-depth interviewees are presented in Table 1. Males and females were equal in number, with ages ranging from 24 to 58 years. Findings from IDIs are presented under seven themes: 1) Awareness and training; 2) Occupational exposure to COVID-19 and duration; 3) Safety measures; 4) Occupational burnout; 5) Social stigma; 6) Psychological violence; and 7) Facilitating factors. Themes and selected quotes are presented in Table 2.

\section{Awareness and Training}

Most of the participants seemed to know regarding COVID-19 through electronic media and a few of them were from the concerned health officials. Since the nature and spread of the virus were still evolving when this study was conducted, participants had different perceptions on the mode of transmission.

These viruses are spreading through the air and you can get this disease when you consume bats (P2).

A majority of the participants were well trained about the field surveillance activities, which included topics on contact tracing, Personal Protective Equipment (PPE) sensitization, disinfection, and appropriate handling of testing samples. 
They explained to us how to do house to house survey and identify high-risk groups: pregnant women, sugar/BP/cancer patients, and provide them with masks (P2).

Table 1. Socio-demographic characteristics of In-Depth Interview (IDI) participants.

\begin{tabular}{|c|c|c|}
\hline \multicolumn{2}{|r|}{ Participants } & \multirow{2}{*}{$\frac{\text { No. of IDI }}{16}$} \\
\hline Number & & \\
\hline \multirow[t]{2}{*}{ Sex } & Male & 8 \\
\hline & Female & 8 \\
\hline \multirow[t]{2}{*}{ Age } & $20-40$ years & 10 \\
\hline & $41-60$ years & 6 \\
\hline \multirow[t]{11}{*}{ Health Care Workers } & District Epidemiologist & 1 \\
\hline & Medical Officer & 1 \\
\hline & Village Health Nurse & 2 \\
\hline & Urban Health Nurse & 4 \\
\hline & Accredited Social Health Activist & 2 \\
\hline & Auxiliary Nurse Midwife & 1 \\
\hline & Sanitary Inspector & 1 \\
\hline & Sanitary Supervisor & 1 \\
\hline & Sanitary Worker & 1 \\
\hline & Ambulance Coordinator & 1 \\
\hline & Emergency Medical Technician & 1 \\
\hline
\end{tabular}

Table 2. Themes and selected quotes from IDIs on occupational exposure to health care workers to COVID-19 during field surveillance activities.

\begin{tabular}{|c|c|c|}
\hline Theme & Sub-theme & Quotes \\
\hline \multirow[t]{2}{*}{$\begin{array}{l}\text { Awareness and } \\
\text { training }\end{array}$} & $\begin{array}{l}\text { Knowledge about } \\
\text { COVID-19 }\end{array}$ & $\begin{array}{l}\text { It is a droplet infection and can spread } \\
\text { through the air }\end{array}$ \\
\hline & Training & $\begin{array}{l}\text { On the first day, they explained to us what to } \\
\text { do and how to conduct the COVID survey }\end{array}$ \\
\hline \multirow[t]{2}{*}{$\begin{array}{l}\text { Exposure and } \\
\text { duration }\end{array}$} & Exposure & $\begin{array}{l}\text { If there is a positive case, special attention is } \\
\text { given to that house. We enter, spray, bleach, } \\
\text { and put a tick mark on the door }\end{array}$ \\
\hline & Duration & $\begin{array}{l}\text { Normally for doing an Antenatal care survey } \\
\text { we used to start by 9:00 am but for COVID } \\
\text { duty we started by 7:00 am }\end{array}$ \\
\hline \multirow[t]{2}{*}{ Safety measures } & $\begin{array}{l}\text { Personal protective } \\
\text { equipment }\end{array}$ & $\begin{array}{l}\text { Within few minutes of wearing disposable } \\
\text { masks, I feel a pungent smell. It is difficult to } \\
\text { even drink water }\end{array}$ \\
\hline & Extra-precautions & $\begin{array}{l}\text { When we went to survey a high-risk area, we } \\
\text { maintained more social distance }\end{array}$ \\
\hline
\end{tabular}




\section{Continued}

\begin{tabular}{|c|c|c|}
\hline \multirow[t]{2}{*}{$\begin{array}{l}\text { Occupational } \\
\text { burnout }\end{array}$} & Overburdened & $\begin{array}{l}\text { Our primary job is to register ten pregnant } \\
\text { women in a month, we are not able to do } \\
\text { that. All the time we are on COVID duty, we } \\
\text { have no time to do our regular work }\end{array}$ \\
\hline & Shortage of workers & $\begin{array}{l}\text { The burden was huge due to lack of } \\
\text { manpower, but they co-operated and } \\
\text { dedicated themselves completely }\end{array}$ \\
\hline Social stigma & Rejection & $\begin{array}{l}\text { Some people even shut their doors, saying } \\
\text { that we are spreading it }\end{array}$ \\
\hline \multirow[t]{2}{*}{$\begin{array}{l}\text { Psychological } \\
\text { violence }\end{array}$} & Emotional trauma & $\begin{array}{l}\text { The public is asking us whether we get paid } \\
\text { separately for collecting samples. I have been } \\
\text { in this service for } 32 \text { years and have been very } \\
\text { honest without taking any bribes, but when } \\
\text { they say this, I feel demotivated and sad }\end{array}$ \\
\hline & Verbal abuse & $\begin{array}{l}\text { We work all day and get told off by people, it } \\
\text { is bad. We control our emotions as this is } \\
\text { part of our job }\end{array}$ \\
\hline \multirow[t]{3}{*}{ Facilitating factors } & $\begin{array}{l}\text { Support from } \\
\text { higher-ups }\end{array}$ & $\begin{array}{l}\text { I got support from my supervisors in the } \\
\text { workplace, from my parents at home }\end{array}$ \\
\hline & Motivation & $\begin{array}{l}\text { When I get up in the morning and wear my } \\
\text { uniform, I forget about all my problems. I do } \\
\text { not care about anything and do my work } \\
\text { quickly }\end{array}$ \\
\hline & $\begin{array}{l}\text { Protection for women } \\
\text { staff }\end{array}$ & $\begin{array}{l}\text { I am always accompanied by a senior Urban } \\
\text { Health Nurse. This allocation was followed } \\
\text { for all the women on COVID field duties. }\end{array}$ \\
\hline
\end{tabular}

\section{Occupational Exposure and Duration}

Participants' exposure to COVID-19 differed, based on their designation and nature of work. Although containment activities were allotted on a shift-basis, their often work extended beyond working hours. Some of them were also denied weekly-off.

Our exposure is high. From sweeping, spraying, and applying bleaching powder on the road we are doing everything. To do this work we have allotted one worker for several houses, in rotation (P12).

We worked from 10:30-1:30 pm and from 4:30-6.30 pm. It was not about the amount of time, really, but the large areas that we had to cover each day, increasing our exposure and burnout (P2).

\section{Safety Measures}

Participants were provided with sufficient Personal Protective Equipment (PPE); however, some people were uncomfortable wearing it. Most participants disposed of the PPE in the designated area while a few burnt it.

They provide gloves, But I don't wear...it makes my hand wet and uncomfortable. Instead, I just sanitize my hand regularly (P1).

To protect themselves and their families from contracting the virus, most par- 
ticipants said they stringently adhered to advisories on social distancing, vehicle disinfection, and maintenance of personal hygiene.

I am staying in my room separately on the terrace. After finishing work, I used to bathe in the bus stand bathroom, go home, and bathe again (P13).

\section{Occupational Burnout}

Due to shortage of trained manpower, most participants reported being unduly burdened with primary health care duties in addition to the COVID-19 related field surveillance activities.

Antenatal care is a separate target for us. Postnatal Care visit is also mandatory. Every morning after COVID survey we used to follow up with pregnant and lactating women (P5).

\section{Social Stigma}

Due to fear and misinformation in the community, frontline workers felt stigmatized and felt that symptomatic people also hesitated to reach out for help.

Some people even shut their doors when we were passing by their homes, shouting "you are spreading the virus, don't come to our area" (P7).

\section{Psychological Violence}

The uncertainty associated with the pandemic seemed to have resulted in respondents' stress affecting their ability to cope with work-related demands.

I feared for my life to go for surveying. Only because it was my duty, I went every day (P3).

During door-to-door surveys, most participants were humiliated by residents thinking that they were duty bearers for the National Population Registry (NPR). Respondents also reported that certain communities were reluctant to share basic demographic details, especially in areas inhabited by religious minorities.

They insulted us thinking that we came to collect NPR data. We put up with the insults with a thick skin (P9).

\section{Facilitating Factors}

Respondents' ability and strength to cope was attributed to their religious belief and perseverance. Despite facing several barriers in the community, most of them managed to perform their duties and continued performing the containment activities, with police protection, family support, and recognition from higher officials.

Our Medical officer sir always monitored and observed each and everyone's work and appreciated us (P2).

\section{Discussion}

The field-level healthcare workers in this study perceived that they had high occupational exposure to COVID-19. They felt stigmatized by residents who believed that health staffs were the main source of infection in the community. HCWs also felt stressed with increased workload due to field surveillance, which was in addition to having to meet their regular work-related targets. Field level activi- 
ties included contact tracing, ante and post-natal visits, immunization, and conducting routine medical camps. Shortage of human resources, not being provided weekly off, and delay in receiving payments seemed to have exacerbated their psychological distress and burnout. They also identified support from supervisors and family, and measures ensuring the safety of women as facilitating factors to cope with the situation.

Other studies found that HCWs face an unprecedented occupational risk of morbidity and mortality especially in the context of COVID-19 [6]. Our study respondents, in addition, also reported work overload. In another study of 1961 healthcare workers, 38.3\% displayed high emotional exhaustion, $46.5 \%$ showed low professional efficacy and $26.5 \%$ revealed cynicism [7]. Burnout was reported in other studies as well [8]. A study from China with 2026 HCWs showed that greater than half of the respondents had pandemic-related burnout. The doctors were 1.64 times, and support staffs were five times more likely to experience pandemic-related burnout than administrative staff.

Misinformation and fear among the public regarding COVID-19 was found to be high in our study. As a result, respondents encountered psychological violence and verbal abuse from the public. Similarly, a study of HCWs working in Delhi during May-July 2020 showed that 70\% of the participants perceived some kind of stigma. The provision of psychological and financial support for health workers is therefore urgently needed [9]. There were initial reports of violence against the healthcare workers across the country, which lead the Indian government to bring in a new Ordinance, which made violence against healthcare workers punishable with up to seven years in prison [10].

The foremost concern that emerged among our study respondents was the fear of contracting the infection and the possibility of transmitting it to their family members. Their awareness regarding the infection was fine, but the preparation was uncertain. Awareness and preparedness for the pandemic were found to be low among frontline workers in another study [11]. Although there were initial reports of shortage of PPE in other areas [12], HCW in our study acknowledged the adequacy of PPE. This is perhaps due to a steady involvement of various domestic companies in the production of PPE after May 2020, resulting in India becoming the second-largest producer of PPE in the world [12]. However, respondents' adherence to wearing gloves and masks seems to be hindered by factors such as skin irritation, feeling of suffocation, and bad odor.

Another study among HCW showed that inadequate supply of PPE, exposure to infected patients, work overload, poor infection control, and pre-existing medical conditions were identified as risk factors for COVID-19, exacerbated by exhaustion due to heavy workloads and protective gear [13].

Despite physical and mental exhaustion, the respondents showed dedication, a strong sense of duty, and resilience to work in the field. They appreciated the support shown by their supervisors at work, and family members at home, labelling these as facilitating factors for handling the uncertainty associated with the pan- 
demic. Similarly, a study in China [13] showed that HCW showed resilience and the spirit of professional dedication to overcome difficulties. The feeling of "this is my duty" was evident in our study too. They also identified many sources of social support and used self-management strategies to cope with the situation like our study found. In addition, immediate condemnation of stigma-related incidents by all stakeholders can reduce stigma and discrimination [14]. The reassurance that the employer is taking measures to take care of them makes the employee less worried about the pandemic's consequences [15].

This study has some limitations. Since we could only conduct telephonic interviews, we may have missed the non-verbal cues and expression of the respondents. The respondents were interviewed only once amid the pandemic, their emotional and psychological responses could have varied if interviewed during the initial or later stage.

This is however one of the first studies in India on perspectives on occupational exposure and safety measures followed during COVID-19 field surveillance activities. The study's strengths are the response from a wide range of field-level HCWs like medical officers, district epidemiologists, community health workers, sanitary workers, emergency medical technicians, and ambulance coordinators, to understand the different perspectives of occupational exposure of HCWs during field surveillance activities. Qualitative methods also helped bring out various nuances and details of their perceptions, and various trials and tribulations of working in the community during the pandemic.

\section{Conclusion}

Healthcare workers involved in field-level activities in two south Indian states felt a high occupational exposure to COVID-19. This was associated with stigma, high workload, and fear of infection. This study underscores the need for psychological and peer support that should be provided to safeguard the wellbeing of healthcare providers, who are braving all risks to keep the population safe.

\section{Acknowledgments}

The authors would like to especially thank Dr. Muthu, municipal health officer, Mr. Iqbal, sanitary inspector and Dr. Munwar, medical officer who gave permission to conduct the study in the midst of pandemic, and would like to thank all the health care workers who participated in the study.

\section{Conflicts of Interest}

The authors declare no conflicts of interest regarding the publication of this paper.

\section{References}

[1] World Health Organization (2020) Contact Tracing in the Context of COVID-19. WHO, 7 p. 
[2] Koh, D. (2020) Occupational Risks for COVID-19 Infection. Occupational Medicine, 70, 3-5. https://doi.org/10.1093/occmed/kqaa036

[3] Perry, H.B., et al. (2016) Community Health Worker Programmes after the 2013-2016 Ebola Outbreak. Bulletin of the World Health Organization, 94, 551-553. https://doi.org/10.2471/BLT.15.164020

[4] Warrier, A. (2020) The Women Warriors Fighting COVID-19 at the Frontline: ASHA Workers Left Without Hope. eSocialSciences, Working Papers, Article ID: 3066.

[5] World Health Organization (2020) Coronavirus Disease (COVID-19) Outbreak: Rights, Roles and Responsibilities of Heath Workers, Including Key Considerations for Occupational Safety and Health. WHO, 2 p.

[6] Mhango, M., Dzobo, M., Chitungo, I. and Dzinamarira, T. (2020) COVID-19 Risk Factors among Health Workers: A Rapid Review. Safety and Health at Work, 11, 262-265. https://doi.org/10.1016/j.shaw.2020.06.001

[7] Gupta, S. and Sahoo, S. (2020) Pandemic and Mental Health of the Front-Line Healthcare Workers: A Review and Implications in the Indian Context amidst COVID-19. General Psychiatry, 33, e100284. https://doi.org/10.1136/gpsych-2020-100284

[8] Khasne, R.W., Dhakulkar, B.S., Mahajan, H.C. and Kulkarni, A.P. (2021) Burnout among Healthcare Workers during COVID-19 Pandemic in India: Results of a Questionnaire-Based Survey. Indian Journal of Critical Care Medicine, 24, 664-671. https://doi.org/10.5005/jp-journals-10071-23518

[9] Behera, D., Praveen, D. and Behera, M.R. (2020) Protecting Indian Health Workforce during the COVID-19 Pandemic. Journal of Family Medicine and Primary Care, 9 , 4541-4546.

[10] Bhowmick, S. (2020) COVID-19: Indian Healthcare Workers Need Adequate PPE. The BMJ Opinion.

https://blogs.bmj.com/bmj/2020/06/19/covid-19-indian-healthcare-workers-need-a dequate-ppe/

[11] Elhadi, M., et al. (2020) Assessment of Healthcare Workers' Levels of Preparedness and Awareness Regarding COVID-19 Infection in Low-Resource Settings. The American Journal of Tropical Medicine and Hygiene, 103, 828-833.

https://doi.org/10.4269/ajtmh.20-0330

[12] News, L. (2020) India COVID-19: Online Survey Shows Not All Is Well on PPE Availability Front.

[13] Liu, Q., et al. (2020) The Experiences of Health-Care Providers during the COVID-19 Crisis in China: A Qualitative Study. The Lancet Global Health, 8, 790-798.

https://doi.org/10.1016/S2214-109X(20)30204-7

[14] Menon, V., Padhy, S.K. and Pattnaik, J.I. (2020) Stigma and Aggression against Health Care Workers in India amidst COVID-19 Times: Possible Drivers and Mitigation Strategies. Indian Journal of Psychological Medicine, 42, 400-401. https://doi.org/10.1177/0253717620929241

[15] Joseph, B., Angeline, N.G. and Arasu, S. (2020) COVID-19-Practicing Prevention in the Workplace. Indian Journal of Occupational and Environmental Medicine, 24, 133-136. https://doi.org/10.4103/ijoem.ijoem $460 \quad 20$

\section{Annexure}

Questionnaire to understand the perception of the health care workers regarding their occupational exposure to COVID-19, including the safety measures used 
during field surveillance activities.

\section{Demographic Datasheet}

1. Name;

2. Age;

3. Gender;

4. Religion;

5. Marital Status;

6. Languages Known;

7. Place of Residence;

8. Education;

9. Occupation;

10. Income;

11. Designation.

\section{Introduction}

1. What is COVID-19? Can you please explain it in your own words?

Probe: When did you first come to know about coronavirus?

What is your source of information?

2. Do you read about evidence-based information on COVID-19?

Probe: where they get such knowledge from (WHO/CDC/Govt of India guidelines, etc).

\section{Training}

3. Were you given training for COVID-19 house to house survey?

4. If so what was the training about?

Probe: Social distance, hand wash, respiratory hygiene, etc.

5. How long was the training conducted?

6. Which part of the training was useful for your field survey?

\section{Duration of Exposure}

7. Since when you have been working on this COVID-19 survey?

8. What are your travel arrangements?

Probe: How did you travel from your home to your workplace (PHC/Survey location) and back?

9. How long do you work in the field visit per day?

10. Can you please elaborate on the activities conducted during the survey?

\section{Precaution and Safety Measures}

11. Do you think wearing PPE will prevent infection?

12. Do you have access to PPE, hand sanitizer, soap?

Probe: Access in the PHC/while moving in the community during field survey

13. What are the safe practices that you are following?

Probe: How they are wearing masks and gloves?

a. Hand wash-before having food, after touching any surfaces; 
b. Social distance;

c. Respiratory hygiene.

14. What are the safety precautions followed by you while moving into the community?

Probe: Social distance, mask, gloves, sanitizer.

15. How did you dispose of the mask and gloves after finishing the survey?

16. While returning home, what are the safety measures you are following?

\section{Stigma}

17. Have you ever faced stigma by anyone during the survey?

18. If so, can you please explain it?

\section{Health Issues}

19. Have you faced any health issues during the survey?

20. Are you troubled by unexplained headaches, stomach or bowel problems, or other physical complaints?

Probe: Do you have any other health problems?

a. Since when you are having this problem?

b. What were the steps taken?

c. Are you stable or not?

\section{Physical Violence}

21. Have you had any instances of violence against you during the survey?

22. If not, have you come across anyone else who had faced violence? Probe: If yes, can you explain how did it happen? And how did you feel about it?

Did you report the incident?

a. What were the steps taken to prevent it from happening again?

b. Were you given police escort?

\section{Psychological Distress}

23. Were you affected psychologically?

24. Probe: if so explain the incident?

25. What were the steps taken?

26. Were you given any psychological help?

a. If so, whether it is offline or online.

27. Do you worry about anything regarding your work?

(Probe: Getting infected/ passing on to family members/ uncertainty, etc).

\section{Post Lockdown}

28. What do you think should be done to make the situation better?

(More training/less working hrs/recognition, etc).

29. Post lockdown: What are your concerns? 